Wolf during eighty years before 1787 give $10^{*} 23$ years (or, if we take nine cycles, 10.43 years) for the mean duration. It is by mixing these two very different means that the Zurich astronomer finds II' $I$ years, a mean that can evidently have no weight given to it. On the other hand, if Dr. Wolf is in error (as I believe he is) as to the existence of a maximum in 1797 , the mean durations for the eighty years after, and for the eighty years before 1787 agree as nearly as the accuracy of the determinations for the beginning of the eighteenth century will admit.

I beg, then, to repeat that since the time when regular series of magnetic observations were commenced, till now, there is no difference whatever between Dr. Wolf and the magneticians as to the synchronism of the two phenomena.

Under these circumstances we come to the questionAre the sun-spot maxima and minima really synchronous with those of the magnetic diurnal oscillations? I have already said that this was so in 1787 ; and, considering only the cases for which we have complete materials for comparison, beginning with Schwabe's observations of sun-spots, it was so for the maxima of $1829,1837,1848$, 1860 , and 1870 , and for the minima of $1824,1833-4(q . p$.$) ,$ $1844,1856,1866$, and it is the case for the minimum at the present time. These coincidences are far more important, as showing a common cause, than may appear at first sight from this summary.

The successive oscillations of the sun-spot variations are not performed in equal times, neither are those of the magnetic variations. Was the duration of the oscillation for the sun-spots only eight years, as from the maximum in 1829 to that of 1837 , so was that for the magnetic variations; did it amount to $12 \frac{1}{2}$ years nearly, for the sun-spots, as from the minimum of 1844 to that of 1856 , this was also the case for the oscillations of the needle. Does the sun-spot variation proceed from a minimum to a maximum within about three and a half years as from $1833-4$ to 1837 , so does the magnetic oscillation. Does the sun-spot variation occupy nearly eight years between a maximum and the following minimum, as from 1848 to 1856 , so does the diurnal oscillation of the needle.

It will be difficult to persuade physicists that, during nearly a century the sun-spot cycle has been shortened or lengthened, and the sun-spot variations have been accelerated or retarded, so nearly together with those of the diurnal oscillations of the magnet, by accidental coincidences. No doubt the admission of the existence of a causal connection between the two phenomena is opposed to the hypothesis, which many other facts render now wholly untenable, that the magnetic variations are due to the heating action of the sun.

I am obliged to Prof. Piazzi Smyth for giving me the occasion to explain a difficulty which has troubled others as well as himself.

January 23

\section{HENRI VICTOR REGNAULT}

THE death of M. Becquerel, alluded to in our last issue, was followed on the 19th inst. by that of his friend and fellow-physicist, M. Regnault, whose name is associated so intimately with the elementary principles of our knowledge of heat. Henri Victor Regnault was born at Aix-la-Chapelle, July 2 $\mathrm{I}, 18 \mathrm{IO}$. His youth was spent in a hard battle against poverty in the effort to maintain not only himself, but his sister. While still a lad he wandered to Paris, and there obtained a position as assistant in the large drapery establishment known as Le Grand Coude, a name familiar at the present day to the lady visitors of Paris. Here ability and fidelity won for him friends, and at the age of twenty he was enabled to gratify his longings for a scientific education, and enter the Ecole Polytechnique of Paris, the Alma Mater of so many famous French savants. After a course of two years here, in 1832 he entered upon active duties in the department of mines, and was absent from Paris for the next eight years. During the latter portion of this time he occupied a professor's chair at Lyons, and had a laboratory at his disposal. Here he embraced the opportunity to enter upon the field of research in organic chemistry, which had just sprung into existence as a branch of chemical science, under the hands of Liebig, Wöhler, Laurent, Dumas, and others. While many of the chemists of the day were engaged in theoretical disputes, and the battle between the electro-chemical theory and the newly-advocated type-theory was being hotly waged, Regnault devoted himself to the accumulation of the facts so sorely needed as foundation-stones by the disputants on both sides. Among his investigations at this time may be mentioned those on the composition of meconine, piperine, cantharidine, and other alkaloids, composition of pectic acid, identity of esquisetic acid with maleic acid, properties of naphthaline-sulpho-acid, \&c. By the action of sulphuric anhydride on ethylene, he obtained the carbylsulphate, $\mathrm{C}_{2} \mathrm{H}_{4} \mathrm{~S}_{2} \mathrm{O}_{6}$, which Magnus prepared later from alcohol. His most valuable researches, however, were on the halogen derivatives in the ethyl-group, especially interesting at the time of their appearance, when the theories of substitution were timidly being advocated. Among these compounds now familiar reagents to the organic chemists were mono-chloro-ethylene-chloride, $\mathrm{CH}_{2} \mathrm{Cl} . \mathrm{CHCl}_{2}$, obtained by the action of chlorine on ethylene chloride, as well as the higher chlorinated derivatives, which offered one of the most striking instances of substitution. These were followed shortly after $\left(183^{8}\right)$ by the classical investigations on the actions of chlorine on ethyl-chloride $\mathrm{C}_{2} \mathrm{H}_{5} \mathrm{Cl}$, in which one by one all of the hydrogen atoms were successively substituted by chlorine, until the limit, $\mathrm{C}_{2} \mathrm{Cl}_{6}$ was reached. Of importance also was the change of ether, $\mathrm{C}_{4} \mathrm{H}_{10} \mathrm{O}$, into perchloroether, $\mathrm{C}_{4} \mathrm{Cl}_{10} \mathrm{O}$. Another interesting series of preparations gave the substituted ethylenes by the action of alkalies on saturated halogen derivatives, ethylenebromide for example, yielding vinyl-bromide, and hydro. bromic acid :-

$$
\mathrm{C}_{2} \mathrm{H}_{4} \mathrm{Br}_{2}+\mathrm{HKO}=\mathrm{C}_{2} \mathrm{H}_{3} \mathrm{Br}+\mathrm{KBr}+\mathrm{H}_{2} \mathrm{O} \text {. }
$$

By this method he discovered vinyl-bremide, vinyl-iodide, vinyl-chloride, dichlor-ethylene, $\mathrm{C}_{2} \mathrm{H}_{2} \mathrm{Cl}_{2}$, and trichlor-ethylene, $\mathrm{C}_{2} \mathrm{HCl}_{3}$. Finally must be mentioned his discovery of carbon-tetrachloride, $\mathrm{CCl}_{4}$, by leading chlorine into boiling chloroform. It is difficult for us at the present day to estimate the importance attached to these discoveries forty years ago, when every new. fact was a glimmer of light to the organic chemist wandering in the dark, and few series of researches have stood the test of time so well as those carried out by Regnault in his Lyons laboratory. The faithful study of minute properties, and the careful attention to physical peculiarities, already gave evidence of the tendencies which were manifested more fully in another branch of science, and the appearance of his papers in the Amnales de Chimie et Physique attracted the attention of the scientific world to the hitherto unknown provincial professor. In 1840 he was elected to replace Robiquet in the chemical section of the French Academy, and was appointed professor in the Ecole Polytechnique. In the following year he was elected to the chair of physics at the College de France. A few years later he became engineer-in-chief of mines, and in 1850 received the order of officer in the Legion of Honour.

With his removal to Paris the field of Regnault's investigations was changed. Like our own Faraday, after having obtained renown as a chemist, he suddenly turned physicist. He was scarcely established in Paris, when he began his famous series of experiments on specific heat. A few years previous, Dulong and Petit had determined the specific heat of a number of elements by 
means of their calorimeter based on the method of cooling, and obtained data sufficiently accurate to warrant the establishment of their law that the product of the specific heat of an element and its atomic weight is a constant. Regnault, after having submitted their method to careful examination, found it useless for the exact determination of the specific heat of solids, and invented in its place the calorimeter bearing his name. It is based on the method of mixtures, viz., of heating a known weight of a substance to a known temperature, immersing it in a known weight of water at a known temperature, and determining the temperature of the mixture. With this apparatus, which is of a somewhat complicated character, in order to reduce to a minimum the possibilities of error, Regnault determined the specific heat of the liquid and solid elements, and of a great variety of compounds. From the comparison of these results he deduced the general law that for all compounds of the same formula and similar chemical constitution the product of the specific heat and the atomic weight is the same. He also confirmed, by his experiments, the hypothesis of Wöstyn, that the elements require the same amount of heat to be raised to a certain temperature, whether free or in combination, and showed, by his more exact results, the general truth of Dulong and Petit's law. In order to overcome the difficulties of determining the specific heat of gases, Regnault contrived aningenious apparatus in which the gases passed through a spiral inclosed in a known weight of water. The volume of gas, its temperature on entering and leaving the apparatus, and the alteration in the temperature of the water supplied the necessary data. By this means he experimented with about thirty-five of the principal gases and vapours, and established the two important laws, $r$, that the specific heat of any gas at constant pressure, whether simple or compound, is the same at all pressures and temveratures; and 2 , that the specific heats of different simple gases are in the inverse ratio of their relative densities. Regnault prepared also an interesting table of the specific heats of various substances in the solid, liquid, and gasecus forms, from which it appears that the specific heat of the same body is commonly greater in the liquid than in the solid state, and always greater than in the gaseous state.

In his experiments upon heat Regnault was led to devise methods of measuring high temperatures accurately, and invented the well-known air thermometer, which can be used at all temperatures below that at which gas softens, and the mercury and hydrogen pyrometers, the latter of which permits the determination of the temperature in a furnace at any instant. In this connection he carried out also an elaborate series of experiments on the density and absolute expansion of mercury from $x^{\circ}$ to $360^{\circ}$, the results of which, as tabulated, are of primary importance in the correction of thermometers and barometers, as well as in a multitude of physical experiments conducted with this liquid, Still more elaborate and exhaustive are the extensive series of determinations in connection with water, its specific heat at various temperatures, the tension of its vapour at various temperatures, and the latent heat of its vapour at various pressures, all of which were designed to serve as fundamental facts upon which to base the action of heat on water for industrial purposes. The specific heat of water was found to increase from $\mathrm{I}$ at $\mathrm{O}^{\circ}$ to $\mathrm{I}$. $\mathrm{OI} 3$ at $100^{\circ}$ and $I .056$ at $230^{\circ}$. For the determination of the tension of steam Regnault contrived a simple apparatus based on the fact that the maximum tension of steam at the boilingpoint is equal to the external pressure, by the aid of which he was able to construct his table of tensions from $0^{\circ} 32$ mill. at $32^{\circ}$ to 20926 mill. at $230^{\circ}$.

The experiments with this apparatus were extended to a number of volatile liquids with the design of testing the truth of Dalton's supposition that the tension of the vapours of all liquids is the same at temperatures equally distant from their boiling points, and the results showed that although not a law, it was very nearly correct for small intervals of temperature in the neighbourhood of the boiling point. A variety of interesting results were also obtained from mixtures of gases and vapours, including the laws that a liquid does not give off a vapour of so high a tension in the presence of a permanent gas as in a vacuum, and that while the tension of the vapours of a mixture of liquids not dissolving each other is equal to the sum of the tensions of its liquids at the same temperature; on the contrary, the tension arising from a mixture of mutually solvent liquids is less than the sum of the individual tensions.

Perhaps the most important of Regnault's experimental investigations was that on the coefficient of expansion for air and other gases, as well as on the compressibility of gases. Dalton, Gay-Lussac, and Rudberg had obtained numbers for the coefficient of expansions differing widely from one another. It was reserved for Regnault to establish by the most delicate experiments the number ${ }^{\circ} 0366_{3}$ as the coefficient of expansion of air, and to show in addition that the law of Dalton and Gay-Lussac with regard to the regularity of expansion among gases was only approximately correct. A similar result was obtained in his investigations on the accuracy of Boyle and Mariotte's Law, on the compressibility of gases.

In addition to the chief lines of research alluded to, Regnault made a variety of interesting experiments on the phenomena produced by heat, and his hypsometer and hygrometer should be mentioned, on account of their simple and practical qualities. Some valuable investigations on the phenomena of respiration were made by him in connection with Reiset, and, together with Dumas, he carried out a lengthy research on illuminating gas.

His most valuable experimental results are collected together in vol. xxi. of the Mémoires of the French Academy, and a continuation is to be found in vol. xxvi. Regnault published, in 1847 , a treatise on chemistry, which has survived numerous editions in France, and been translated into German, English, Dutch, and Italian.

In I 54 he was appointed director of the famous porcelain manufactory of Sèvres, and since that date much of his time has been devoted to improvements in ceramic processes. During the Franco-Prussian war he received a sad blow in the death, on the battle-field, of his second son, Henri Regnault, a promising artist, and universal favourite in Paris. He returned to his laboratory at Sèvres, after the declaration of peace, to find that the results of his last great research on the phenomena of heat accompanying the expansion of gases, derived from over 600 observations, had been destroyed. The announcement of this loss was his last communication to the scientific world. Since then, oppressed by grief and a victim to increasing infirmities, he has been forced to renounce his wonted pursuits. On the day when the gay artist world of Paris was celebrating the battle of Buzenval by laying wreaths on the grave of the young patriot-painter, the father was released from a long and painful illness by the hand of death.

As a scientific investigator, Regnault did not possess the brilliant originality of many of his fellow-physicists. It is as the patient, thorough, conscientious observer that he has won his way to the foremost rank. Possessing a wonderful ingenuity in the invention of mechanical appliances for the purposes of observation and a perfect familiarity with the mathematical department of physics, he has been enabled by means of his unflagging enthusiasm and unbending resolution to place the modern physicist and chemist in possession of an invaluable collection of constants, which at the present stage of science are in daily use not only in the laboratory of research, but for a large variety of industrial purposes.

T. H. N. 